\title{
Öffentliches Kulturrecht
}

Materielle und immaterielle Kulturwerke zwischen Schutz, Förderung und Wertschöpfung

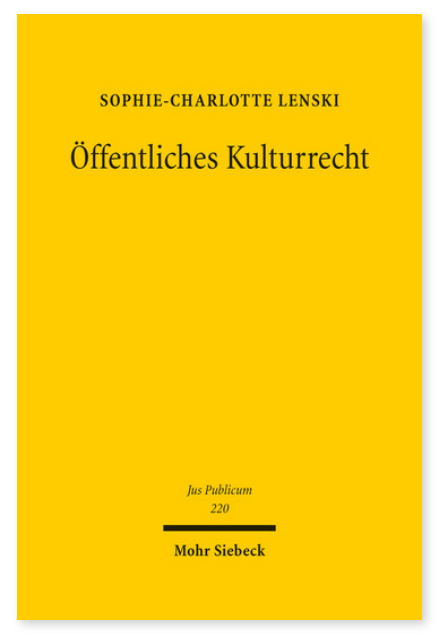

2013. XXVII, 548 Seiten. JusPubl 220

ISBN 978-3-16-152307-6

DOI 10.1628/978-3-16-152307-6

eBook PDF 134,00€

ISBN 978-3-16-152044-0

Leinen $134,00 €$
Wie verhält sich der tatsächliche Befund eines maßgeblich von öffentlichen oder jedenfalls öffentlich geförderten Kultureinrichtungen geprägten kulturellen Lebens zu dem künstlerischen und kulturellen Freiheitsparadigma, das dem Grundgesetz zugrunde liegt? Sophie-Charlotte Lenski rekonstruiert vor dem Hintergrund dieser Frage ein einheitliches Recht der Kulturverwaltung, in dessen Mittelpunkt die Zeichenfunktion von Kulturwerken als zentrales Unterscheidungsmerkmal steht. Den politischen wie rechtlichen Widerstreit zwischen der Bewahrung von Vorhandenem und der Schöpfung von Neuem, zwischen Schutz und Förderung von Kultur, löst sie dabei über das verbindende Element der geistigen Wertschöpfung und legt so den Blick frei auf den Konflikt zwischen gesellschaftlicher Funktionalisierung der Kultur und kultureller Freiheitsentfaltung des Einzelnen.

Sophie-Charlotte Lenski Keine aktuellen Daten verfügbar.

Jetzt bestellen:

https://mohrsiebeck.com/buch/oeffentliches-kulturrecht-9783161523076?no_cache=1

order@mohrsiebeck.com

Telefon: +49 (0)7071-923-17

Telefax: +49(0)7071-51104 